\title{
Major Hepatectomy without Allogeneic Blood Transfusion for Hepatocellular Carcinoma
}

\author{
Jing An Rui \\ Peking Union Medical College Hospital \\ Chinese Academy of Medical Sciences
}

China

\section{Introduction}

Hepatocellular carcinoma (HCC) is the fifth most common cancer in the world and the third leading cause of cancer-related deaths. More than $80 \%$ of HCC cases are from the Asian and African continents, and more than $50 \%$ of cases are from mainland China. It is estimated that more than $50 \%$ of liver cancers worldwide are attributable to HBV and up to $89 \%$ of HBV-related HCC are from developing countries. Recently, increasing trends in HCC incidence have been reported from several Western countries, including France, Australia, and the United States, mainly because of the rising incidence of HCV (McClune \& Tong, 2010). At least one million new cases of HCC occur annually and mortality from this disease remains high (Munoz et al., 1988; Rustgi, 1987; Simonnetti et al., 1991). Surgery, including hepatectomy and transplantation, remains the main curative strategy for hepatocellular carcinoma. The history of hepatic surgery is strongly involved with the history of use of bleeding-control during hepatic operations. In the early 1900s a small but significant step forward was made in liver surgery by J. Hogarth Pringle, who in 1908 described a method for digital compression of the hilar vessels to control hepatic bleeding from traumatic injuries. Credit for the first anatomic liver resection is usually given to Lortat- Jacob, who performed a right hepatectomy in 1952 in France. Wang Chen En in 1961 was first to report a successful hepatic resection for liver cancer in China.

Blood loss during liver resection is one of the most important factors affecting the perioperative outcomes of patients undergoing liver resection. It has been accepted that intraoperative blood transfusion is a risk factor for tumor recurrence, and that infiltrative tumor type, surgical margin $<10 \mathrm{~mm}$ and intraoperative blood transfusion are independent prognostic factors for overall survival.

\subsection{Background}

Blood transfusion has been found to be a highly significant factor which influences outcome of hepatectomy, and major bleeding and major blood transfusion during major hepatectomy are of especial importance. 
The long-term survival of patients with hepatocellular carcinoma after hepatectomy depends on tumor staging, hepatic functional reserve before operation and history of blood transfusion. Preventing major intraoperative bleeding and avoiding allogeneic blood transfusion can significantly improve the disease free and overall survival rates in HCC patients. Rui et al., reported (Rui et al.; 2004) that major hepatectomy without allogeneic blood transfusion can reduce postoperative morbidity and recurrence rate of patients with HCC.

\subsection{Selection of patients for right-trisectionectomy of huge liver tumor}

Up to now, treatment of huge liver cancers is still very difficulty due to poor outcomes and higher mortality and mobidity (Hanazaki et al, 2001; Regimbeau et al, 1999). Since the middle of last century the right trisetionectomy (previous trisegmentectomy) has been used for huge hepatic neoplasms which involve the right and left medial sections of the liver (Quattlebaum 1953). Starzl described and clearly defined in detail a safe technique for right trisectionectomy (Starzl et al 1975). Most reports have indicated that right trisectionectomy is effective for extensive hepatic malignancy, based on patients who have had long-term survival after this operation (Sugiura et al., 1994; Yamamoto et al 1995). Rui reported on a retrospective series of patients in which thirty three cases of right trisectionectomy were all performed under normothermic interruption of the porta hepatis at single time for huge primary liver cancer. The 1-, 3- and 5- year survival rates after right trisectionectomy were $71.9 \%, 40.6 \%$ and $34.4 \%$, respectively. Among the 33 cases of right trisectionectomy, 2 cases did not utilize allogeneic blood transfusion and had good recoveries (Rui et al., 2003). Up to now, the longest cancer free survival in our series is 23 years. This patient is still alive in Beijing.

The feasibility of right trisectionectomy for a given patient must be carefully evaluated according to the following criteria: (1). Tumor(s) (including less than 2 satellite nodules) limited to the right lobe and left medial portion of the liver. There must be no evidence of cancer invasion in the left lateral segment; (2). Tumor mass must have clear borders or a pseudocapsule, and there must be no tumor thrombus in the trunk of the portal vein and hepatic vein, but liver resection remains the only therapeutic option that may offer a chance of cure for HCC with PVTT (Lau WY et al 2008). There were 17 cases (51.5\%) with tumor thrombi in the right branch of the portal vein in our right trisectionectomy patients (Rui JA et al 2003). (3). There must be no evidence of distant metastasis; (4). Compensatory enlargement of the left lateral section should be obvious; (5). The Child-Pugh classification of liver function must be " $\mathrm{A}$ " and the indocyanine green retention rate (ICGR 15) at 15 minutes should be lower than $15 \%$ before surgery; (6). During the Child-Pugh classification of liver function is " $\mathrm{A}$ " and ICGR is less than $15 \%$, the remnant liver volume can be at least $25 \%$ of whole liver. The CT volumetry can be utilized to determine the liver and tumor volume before surgery (Mandli et al 2008).

\section{Surgical technology for major hepatectomy without allogenic blood transfusion}

Major hepatectomy has recently been defined as a resection of four or more liver segments (Reddy et al., 2011) which differs from the former definition of "resection of three liver 
segment". Based on the evaluations of CT volumetry and liver functions (including ChildPugh classification and ICGR test) the major hepatectomy under single time interruption of porta hepatis (continuous Pringle) can be done safely.

Control of hemorrhage is the key factor in liver resection for HCC. Blood loss of more than $1000 \mathrm{ml}$ is defined as major bleeding. In patients with risk factors for bleeding, it is necessary to take effective steps in order to minimize intraoperative blood loss in hepatectomy for patients with HCC, so that allogeneic blood transfusion can be avoided. Surgeons play an important role in avoiding allogeneic blood transfusion and thus improving the prognosis of these patients. Rui performs major hepatectomy without allogeneic blood transfusion via a number of surgical techniques, including normothermic interruption of the porta hepatis at a single time and application of supplementary instruments. Moreover, the surgical procedures characterized by single time interruption of the porta hepatis for major hepatectomy, including right trisectionectomy have been used in more than thirty county and town hospitals located in thirteen provinces in China and have been demonstrated to be feasible and successful.

\subsection{Surgical procedures characterized by single time interruption of the porta hepatis is requisite for major hepatectomy without allogeneic blood transfusion}

Foster said: "Surgical technique is an art form. It can be very personal, based mostly on experience, or it can take a cookbook approach. For many standard operations, we follow in the ruts created by our teachers, perhaps adding a nuance or two called forth by an unusual situation or by a creative mind. Unfortunately, many years ago when I needed help, there was no available to teach me to operate on the liver." (Foster, 1989).

179 cases of hepatectomy for huge HCC were performed in our hospital from January 1995 to December 2002. Among these patients, 155 ( 86.6\%) cases were males and $24(13.4 \%)$ females, with ages ranging from 15 to 77 years (mean \pm SD, $56.3 \pm 13.7$ years). $138(77.1 \%)$ were hepatitis B surface antigen (HBsAg) positive and $144(80.4 \%)$ had liver cirrhosis. 165 patients (92.2\%) were evaluated as grade A and 14 (7.8\%) were grade B in the Child-Pugh's classification prior to surgery. Tumor sizes ranged from 5 to $30 \mathrm{~cm}$ (mean $\pm \mathrm{SD}, 7.9 \pm 4.6 \mathrm{~cm}$ ). Serum alpha-fetoprotein (AFP) in 63 patients (35.2\%) was higher than $400 \mathrm{ng} / \mathrm{ml}$ and 75 patients were TNM stage II, 60 were stage III, 37 were stage IVa, and 7 were stage IVb. These hepatectomies were all performed under single time normothermic interruption of the porta hepatis. Interruption of flow through the porta hepatis lasted 15 to 40 minutes (mean $\pm S D$, $25.3 \pm 6.8$ minutes). The ultrasonic dissector (CUSA System 200) was applied for dissecting hepatic parenchyma. These hepatectomy procedures included right trisectionectomy in 23 patients, left trisectionctomy in 4 patients, extended right hepatectomy in 11 patients, extended left hepatectomy in 3 patients, central hepatectomy in 4, right hepatectomy in 30, and left hepatectomy in 14 patients. The postoperative complication rate was $10.6 \%$ (19/179), and operative mortality was $1.1 \%$. Postoperatively, overall and cancer-free survival rates at $1,2,3,4$ and 5 years were $82.0 \%, 56.7 \%, 51.1 \%, 46.2 \%$ and $40.2 \%$; and $73.1 \%$, $53.2 \%, 46.0 \%, 44.5 \%$ and $38.1 \%$, respectively (Zhou et al., 2007). These results demonstrate that hepatectomy applying normothermic continuous single interruption of the porta hepatis, but not intermittent multiple occlusions of hepatic inflow is safe and tolerable for selected patients with HCC including many who also have cirrhosis. 
At the same time, no damage to the liver has been found by either the electron microscopic examination of liver tissue biopsies or by liver function tests within 20 minutes of single time normothermic interruption of the porta hepatis. Our clinical practice has shown that a single time 20-42 minute normothermic interruption of the porta hepatis is safe with use of skilled surgical technique. Since 1984 we have applied single time normothermic interruption of the porta hepatis for all surgical hepatectomy procedures. We have carried out one hundred cases of hepatic resection without mortality under single time normothermic interruption of the porta hepatic in a period of 4 years (1984-1988), and our subsequent surgical mortality has been shown to be less than $1.3 \%$.

Diminished bleeding by applying single time interruption of porta hepatis serves to avoid allogeneic blood transfusion during liver resection. We have conducted a retrospectively study of 51 patients who received hepatectomy without allogeneic blood transfusion. Of these patients whose ages ranged from 24 to 77 years (mean 46.5 years), 40 were men and 11 were women. Clinical diagnosis showed primary liver cancer in 29 patients, metastatic liver cancer in 6, hepatic hemangioma in 10, and benign hyperplasia in 6. TNM staging of the primary liver cancer showed 15 patients were stage II $(51.8 \%), 10$ patients were stage III (34.5\%), and 4 were stage IVa. The mean tumor diameter was $8.7 \mathrm{~cm}$ (range 6.5 to 18 $\mathrm{cm})$. Preoperative Child-Pugh classification for liver function was grade A in 34 patients $(66.7 \%)$ and grade B in 17 (33.3\%). Surgical procedures included right trisectionectomy in 2 patients $(3.9 \%)$, right lobectomy in $6(11.8 \%)$, left lobectomy in $7(13.7 \%)$, medial hepatectomy in $3(5.9 \%)$, and trisegmentectomy in $33(64.7 \%)$. The mean operative time was 181 minutes (range 90 to 300 minutes). Single time normothermic interruption of the porta hepatis was applied in all procedures, with a mean interruption time of 16 minutes (range 8 to 35 minutes). The ultrasound dissector (CUSA System 200) was used for dissecting parenchyma of the liver, and intraoperative ultrasonography was used for localization of tumors. The mean blood loss was $755 \mathrm{ml}$ ( range 400 to $2000 \mathrm{ml}$ ). Thirtytwo patients $(63.0 \%)$ accepted autologous blood transfusion (mean volume, $326 \mathrm{ml}$; range 200 to $600 \mathrm{ml}$ ). Pathologic examination showed hepatocellular carcinoma in 27 patients, mixed hepatocellular-cholangiocarcinoma in 2, liver metastasis of malignancies from colorectal cancer in 6 patients, hepatic cavernous hemangioma in 10 patients, and hepatic focal nodular hyperplasia in 6 . At the same time there were 60 patients in the control group who received hepatectomy with allogeneic blood transfusion, including 48 cases of primary liver cancer. Blood was transfused routinely if the haemoglobin level fell to < $8 \mathrm{~g} / \mathrm{dl}$. Fresh frozen plasma was transfused if the prothrombin time rose to $>30 \mathrm{~s}$. As a result the operative mortality and morbidity rates in the study group (without allogeneic blood transfusion) were $\mathrm{o} \%$, and $9.8 \%$ respectively, while in the control group (allogeneic blood transfusion) mortality and morbidity were $3.3 \%$ and $28.3 \%$, respectively. Cancer recurrence within three years was discovered in 9 of 51 pateints in the study group. The 1 , 2 and 3 year cancer recurrence rates in the study group were $24.1 \%, 27.6 \%$, and $31.0 \%$, respectively; while in the control group 27 of 46 patients had tumor recurrence in the same period, and the 1, 2 and 3 year recurrence rates were $43.5 \%, 54.3 \%$ and $58.7 \%$, respectively. Significant differences $(p<0.05)$ were present between these two groups (Rui et al., 2004) demonstrating the advantages of major hepatectomy applying single interruption of porta hepatis without allogeneic blood transfusion. 


\subsection{Application of supplementary instruments}

\subsubsection{Intraoperative ultrasound}

Intraoperative ultrasonography (US) of the liver provides the surgeon with useful real-time diagnostic and staging information that may result in an alteration of the planned surgical approach. Current applications for intraoperative US of the liver include evaluation of tumor staging and metastatic survey, guidance for metastasectomy and various tumor ablation procedures, documentation of vessel patency, evaluation of intrahepatic biliary disease, and guidance for whole-organ or split-liver transplantation. To obtain the most useful information with intraoperative US, the sonographer must use a dedicated transducer and a scanning method appropriate for the purpose of the examination. Motohide applied 3DUS in 24 patients undergoing hepatic resection, and found that this technique allowed easy visualization of the tumors and vascular anatomy. It is thus considered to be an efficient and safe navigation system in liver surgery (Motohide et al., 1998). In addition, application of intraoperative US of the liver with current transducer resolution permits the identification of lesions larger than $2 \mathrm{~mm}$. Sensitivity of more than $90 \%$ has been documented for detection of lesions in the liver, with positive and negative predictive values of $90 \%$ and $78 \%$, respectively (Guimaraes et al., 2004). Since 1983, we have utilized intraoperative ultrasonography of the liver for patients with liver tumors. The sensitivity is more than $90 \%$ in our series which is consistent with what reported by Zacherl (2002).

\subsubsection{Ultrasound dissector for dissecting parenchyma of the liver}

Since November 1992 we have applied the ultrasonic dissector (CUSA system 200) for dissecting hepatic parenchyma, instead of using the previous finger fracture technique. Combined application of single time interruption of the porta hepatis and ultrasonic dissector can reduce intraoperative bleeding in liver resection. The advantages of applying this technique are: (1) It can reveal small vessels and segments of the biliary tree which are less than 2mm; (2) It allows damage to the portal vein and hepatic vein to be diminished resulting in less blood loss; (3) It promotes quick portal hepatic dissection and tumor resection. However, the disadvantage may be prolongation of operating time.

Fan reported that they performed major hepatectomy in 69 patients with the assistent of the ultrasonic dissector, and found that it is better than the crushing clamp and finger fracture technique in hepatectomy for hepatocellular carcinoma (Fan et al., 1996).

\subsubsection{RF (radiofrequency) assisted liver resection technique}

Milicevic et al reported that the sequential coagulate-cut, RF-assisted liver resection technique is a safe liver transection technique associated with minimal blood loss and it has facilitated tissue-sparing liver resection (Milicevic et al., 2007). Navarra reported RF-assisted liver resection (Navarra et al., 2004), in which the median resection time was 47.5 minutes (range 30-110) with median blood loss of $30 \mathrm{mls}$ (range 15-992) and mean pre-operative and post-operative hemaglobin values of $13.5 \mathrm{~g} / \mathrm{dL}(\mathrm{SD} \pm 1.7)$ and $11.6 \mathrm{~g} / \mathrm{dL}(\mathrm{SD} \pm 1.4)$ respectively. No blood transfusion was registered, nor was any mortality observed. There was one post-operative complication which was a sub-phrenic abscess. The median post- 
operative stay was 8 days (range 5-86). Long reported: Over the past few years, a new technique for liver resection assisted with radiofrequency has been developed at the author's hospital, expanding the role of radiofrequency in liver surgery from mere tumor ablation to routine hepatic resection ( Long R Jiao et al 2008 ). Ayav concluded that major hepatectomy using RF can decrease the rates of blood transfusion, postoperative liver failure, ICU admission, and postoperative stay. Moreover the price is significantly lower as compared to total vascular exclusion (Ayav et al., 2007).

\section{Advantages from single time interruption of the portal hepatis without allogeneic blood transfusion in hepatectomy}

\subsection{Advantages from single time interruption of the porta hepatis}

Since there is a lack of donors for liver trasplantation, liver resection continues to be the first choice for patients with resectable hepatocellular carcinoma with liver cirrhosis but compensated liver function. Univariate analysis has shown that the presence of portal vein tumor thrombosis and satellite nodules, high TNM stage, high Edmondson-Steiner grading, and blood transfusion are all associated with worsened prognosis (Zhou et al., 2007).

In a period of 8 years (from January 1995 to 2002) we successfully performed major hepatectomy in 81 patients with HCC combined with cirrhosis applying normothermic continuously single interruption of the porta hepatis. The mortality and morbidity rates were $1.2 \%$ and $24.7 \%$ respectively, indicating that the procedure can be carried out safely. Less blood loss and shorter operating time have been achieved in our cohort.

The significance of intermittent hepatic inflow occlusion for safe hepatectomy has been generally recognized (Man et al., 2003). Some surgeons have argued that intermittent interruption of flow through the porta hepatis leads to less liver injury during hepatic resection than with continuous flow interruption (Belghiti et al., 1999). Belghiti and Pol reported that the mean ischemic time under intermittent interruption of flow through the porta hepatis for hepatectomy was approximately $40 \mathrm{~min}$ (Belghiti et al., 1999; Pol et al., 1999), which is far longer than the mean ischemic time of 20.6 min that we reported with a single interruption of the porta hepatic for major hepatectomy. Our experience is similar to results of a recent prospective, randomized clinical trial from Italy (Capussotti et al., 2003). It is established that major hepatectomy under normothermic continuous interruption of flow through the porta hepatis is well tolerated by HCC patients, including those with liver cirrhosis, when the interruption time was well controlled. Thus, intermittent interruption of the porta hepatis may not be necessary (Zhou et al., 2007). It is easily understood that compared with intermittent multi hepatic inflow occlusions, continuous single interruption can simplify procedures, shorten operating time, and reduce blood loss, especially during transaction of liver parenchyma.

It is well known that reperfusion injury following ischemia is a clinically important process that contributes significantly to tissue damage (Mitchell \& Cotran, 2003). Single time interruption of the porta hepatis during liver resection not only diminishes blood loss, but also attenuates reperfusion injury following ischemia as compared with multi-interruption of the porta hepatis. 


\subsection{Advantages of avoiding allogeneic blood transfusion}

We have successfully performed major hepatectomy applying single time normothermic interruption of the porta hepatis in 51 patients without allogeneic blood transfusion, and have effectively limited intraopertive bleeding. It is evident that postoperative complications of major hepatectomy can be markedly reduced, recurrence rate can be decreased, and mortality can be decreased by avoiding allogeneic blood transfusion. Our results confirmed the conclusion that perioperative allogeneic blood transfusion is responsible for a relatively poor prognosis.

Poon reported that in a prospective study of 377 patients over 10 years, absence of perioperative transfusion is an independent favorable prognostic factor for disease-free survival, and improves survival results after resection for HCC (Poon et al., 2001).

\subsection{Immunomodulation and blood transfusion}

It is known that allogeneic blood transfusion-associated immunomodulation has been associated with alterations in immune function in transfusion recipients, including decreased ratio of helper T-lymphocytes to suppressor T-lymphocytes, attenuated function of natural killer cells, defective antigen presentation, and reduction in cellmediated immunity (Blajchman, 2002). Perioperative allogeneic blood transfusion may play an important role in suppressing the host immune system, for example by decreasing natural killer cell activity (Hanna et al., 1980; Herberman, 1984) and/or increasing suppressor T-cell activity and inhibition of lymphocyte transformation, thereby diminishing specific and non-specific immune responses. These effects are possibly due to the cytological and immunological factors for tumor recurrence after blood transfusion allowing for progression of residual cancer and leading to a poor prognosis (Kaplan et al., 1984). Therefore, it is suggested that avoiding intraoperative and perioperative allogeneic blood transfusion is beneficial to patients with resectable HCC, particularly to those with large tumors (Rui et al., 2004; Sugita et al., 2007). For a better prognosis including prevention of recurrence and metastasis, and prolongation of survival time, the surgeon must master skilled surgical techniques, and apply suitable surgical procedures and supplementary instruments for hepatectomy, especially for major hepatectomies. In summary, hepatectomy without allogeneic blood transfusion is advantageous to diminishing surgical complications and improving the prognosis of HCC patients (Kaplan et al., 1984; Rui et al., 2004).

\section{Case report}

Case 1: A 15 years old boy was diagnosed with hepatocellular carcinoma, and a right trisectionectomy was performed with single time interruption of the porta hepatis. The resected tumor weighted $2000 \mathrm{gm}$ (Figure1). The postoperative cancer free survival time was 6 years and the patient died of non-neoplastic disease.

Case 2: A 57 years old woman was diagnosed with hepatocellular carcinoma, and a right trisectionectomy was performed with single time interruption of the porta hepatic in 1988. The resected tumor weighted 2200gm (Figure2). She is still alive in Beijing 23 years after right trisectionectomy without recurrence. 


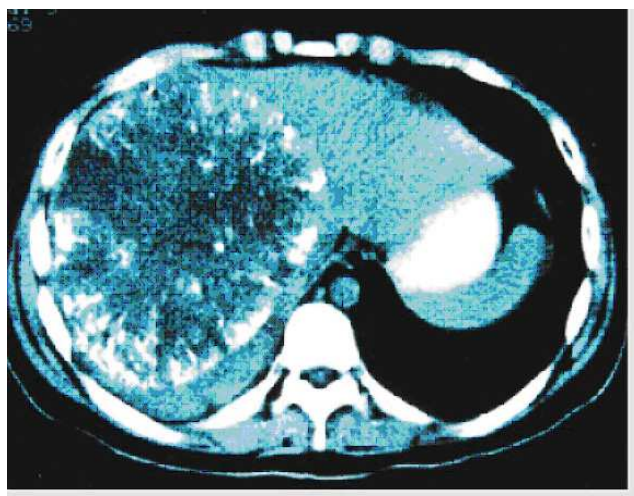

CT

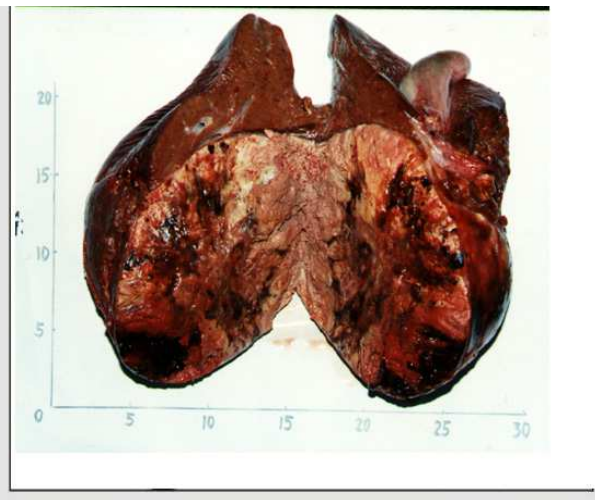

\section{Specimen}

Fig. 1. The resected tumor tumor weighted $2000 \mathrm{gm}$ from a 15 years old boy. This patient was operated for right trisectionectomy under single time interruption of the porta hepatis, and postoperative cancer free survival for 6 years, died of noncancerous disease.

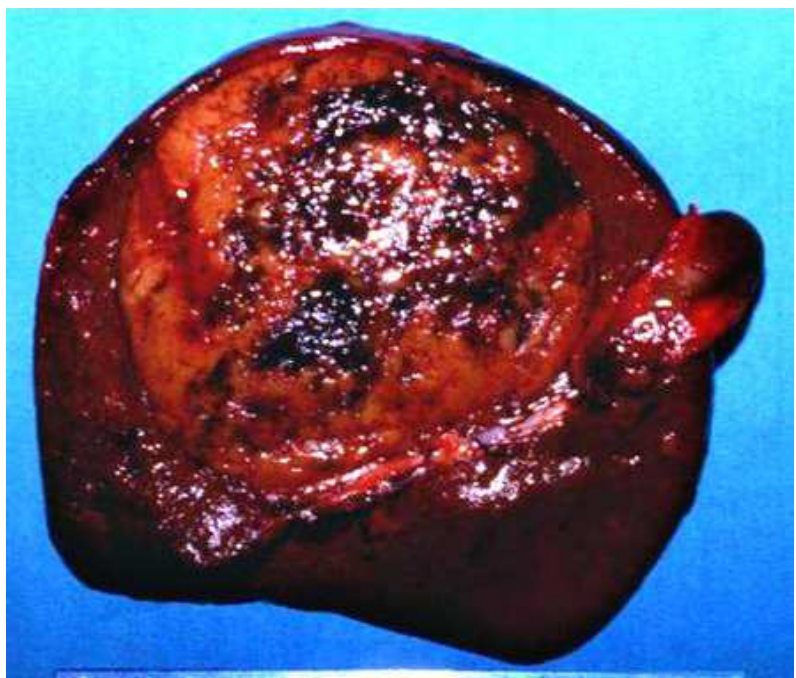

Fig. 2. The resected tumor weighted $2200 \mathrm{gm}$ with a diameter of $15 \times 18 \mathrm{~cm}$ from a 57 years old woman. This patient was operated for right trisectionectomy under single time interruption of the porta hepatis in 1988 and is still alive in Beijing 23 years after right trisectionectomy.

Case 3: A 24 years old man was diagnosed with hepatocellular carcinoma. A right trisectionectomy was performed under single time interruption of the porta hepatis, loss blood of intraoperation $1500 \mathrm{ml}$, accepted autologous blood transfusion $600 \mathrm{ml}$, without allogeneic blood transfution. The resected tumor weighted $2500 \mathrm{gm}$ (Figure3). The patient was discharged from hospital after recovery at 32 days after operation. 


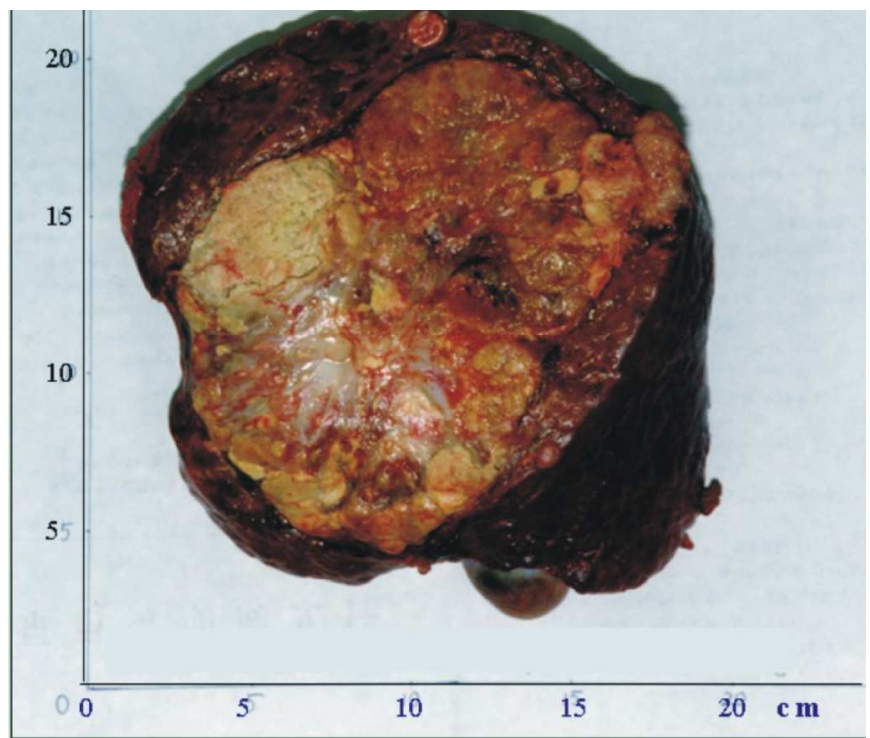

Fig. 3. The resected tumor weighted $2500 \mathrm{gm}$ with a diameter of $17.5 \mathrm{X} 13.7 \mathrm{~cm}$ from a 24 years old man. This patient was operated for right trisectionectomy under single time interruption of the porta hepatis without allogeneic blood transfusion and discharged from hospital after recovery at 32 days after operation. The pathologic disnosis was hepatocellular carcinoma.

\section{References}

Ayav, A., Navarra, G., Basaglia, E., Tierris, J., Healey, A., Spalding, D., Canelo, R ., Habib, NA. \& Jiao, LR. (2007). Results of major hepatectomy without vascular clamping using radiofrequency-assisted technique compared with total vascular exclusion. Hepatogastroenterology.Vol. 54 , No.75, pp.806-809.

Belghiti, J., Noun, R., Malafosse,R., et al. (1999). Continuous versus intermittent portal triad clamping for liver resection : a controlled study . Ann Surg,Vol. 229, pp. 369- 375.

Blajchman, MA. (2002). Immunomodulation and blood transfusion. American Journal of Therapeutics. Vol.9, No.5, pp.389-395.

Capussotti, L., Muratore, A., Massucco, P, et al. (2004). Major liver resections for hepatocellular carcinoma on cirrhosis : early and long-term outcomes. Liver Transpl. Vol.10 ( Suppl 1 ), pp. 64-68。

Capussotti, L., Nuzzo, G., Polastri, R., et al. (2003) Continuous versus intermittent portal triad clamping during hepatectomy in clinical trial. Hepatogastroenterology. Vol. 50, pp.1073-1077.

Foster, JH. (1989). Liver Resection Techniques .Surgical C linics of North America. Vol. 69, No. 2, pp. 235-249. 
Fan, ST., Lai, EC., Lo, CM., Chu, KM., Liu, CL.,\& Wong, J. (1996). Hepatectomy with an ultrasonic dissector for hepatocellular carcinoma. Br J Surg, Vol. 83, No.1, pp.117120.

Guimaraes ,CM., Correia, MM.,\& Baldisserotto, M.( 2004). Intraoperative ultrasonography of the liver in patients with abdominal tumors : a new approach. J Ultrasound Med, Vol.23, pp.1549-1555.

Hanazaki, K., Kajikawas, S. \& Shimozawa, N. ( 2001). Hepatic resection for large hepatocellular carcinoma. Am J Surg, .Vol. 181, pp. 347-353.

Herberman, RB., (1984). Natural killer cells and their possible roles in host resistance against tumors. Transplant Proc, Vol.16, pp.476-478.

Hanna, N., Fidler, IJ. ( 1980 ). Role of natural killer cells in the destruction of circulating tumor emboli. J Natl Cancer Inst, Vol.65, pp.801-809.

Kaplan, J., Sarnaik, S., Gitlin, J. \& Lusher, J. (1984 ). Diminished helper/suppressor lymphocyte ratios and natural killer activity in recipients of repeated blood transfusion. Blood, Vol.64, pp.308-310.

Li, CH., Chau, GY., Lui ,WY., Tsay, SH., King, KL., Hsia, CY. \& Wu, CW. (2003). Risk factors associated with intra-operative major blood loss in patients with hepatocellular carcinoma who underwent hepatic resection. Journal of the Chinese medicine Assocication: JMCA.Vol. 66, No.1, pp. 669- 675.

Lau, WY., Lai, Eric CH. \& Yu, Simon CH. (2008). Management of Portal Vein Tumor Thrombus, In: Hepatocellular carcinoma, Lau WY, pp.739-760, World Scientific, Singapore.

Long, R.Jiao. \& Habib, NA. (2008). Radiofrequency-Assisted Liver Resection, In: Hepatocellular carcinoma, W.Y. Lau, pp.551-567, World Scientific, Singapore.

Munoz, N. \& Bosch, X.. (1988). Epidemiology of hepatocellular carcinoma. In: Okuda, K., Ishak, KG. eds. Neoplasms of the liver. Springer-Yerlag, Berlin, Germary, pp.3-19.

Man, K., Lo, CM., Liu, CL, et al . (2003) Effects of the intermittent Pringle manoeuvre on hepatic gene expression and ultrastructure in a randomized clinical study. $\mathrm{Br} J$ Surg.Vol. 90, pp.183-198.

Mandli T, Fazakas J, Ther G. et al. (2008). Evaluation of liver function before living donor liver transplantation and liver resection. Orv Hetil. Vol.149, No.17, pp.779-786.

McClune, AC. \& Tong M J. ( 2010). Chronic Hepatitis B and Hepatocellular Carcinoma, Clinics in Liver Disease, Vol.14, No. 3, pp. 461-476

Mitchell, RN. \& Cotran, RS. (2003). Cell injury, adaptation and death, In: Basic Pathology (7th edition), Kuman Vinay, Cotran Ramzi S. and Robbins Stanley L., pp.9, Elsevier, ISBN: 0-7216-9274-5, Singapore

Milicevic, M., Bulajic, P., Zuvela, M., Dervenis, C., Basaric ,D. \& Galun, D. (2007). A radiofrequency-assisted minimal blood loss liver parenchyma dissection technique. Digestive Surgery, Vol.24, No.4, pp.306-313.

Morris A Blajchman. (2002). Immunomodulation and Blood Transfusion. America Journal of Therapeutics, Vol.9, No. 5, pp. 389-395.

Motohide, S., Go, W., Masahiro, O., Hiroshi, H. \& Masaki, K. (1998)Clinical application of three-dimensional ultrasound imaging as intraoperative navigation for liver surgery. Nihon Geka Gakkai Zasshi. Vol.99, No.4, pp.3-7. 
Navarra, G., Lorenzini, C., Currò, G., Sampiero, G., \& Habib, NH., (2004). Radiofrequencyassisted hepatic resection--first experience. Ann Ital Chir, Vol.75, No.1, pp.53-67.

Pringle, JH. (1908). Notes on arrest of hepatic hemorrhage due to trauma. Ann Surg ,Vol.48, pp.541-549.

Pol, B., Campan, P., Hardwigsen, J., et al. (1999). Morbidity of major hepatic resections: a 100-case prospective study. Eur J Surg, Vol.165, pp. 446-453.

Poon, RT., Fan, ST., Lo, CM., Ng, IO., Liu, CL., Lam ,CM. \& Wong,J. (2001). Improving survival results after resection of hepatocellular carcinoma: a prospective study of 377 patients over 10 years. Ann Surg, Vol. 234, No.1, pp. 63-70.

Quattlebaum,JK. (1953) .Massive resection of the liver. Ann Surg, Vol. 137. pp.787-796.

Reddy, SK., Barbas, AS., Turley, RS., Steel, JL., Tsung, A., Marsh, JW., Geller, DA. \& Clary,BM. (2011). A standard definition of major hepatectomy: resection of four or more liver segments. HPB, Vol.13, N0. 7, pp. 494-502.

Rustgi, VK. (1987). Epidemiology of hepatocellular carcinoma. Gastroenrol, Clin North Am . Vol.16, pp. 545-551

Rui, JA., Wang, SB., Chen, SG., \& Zhou, L . (2003). Right trisectionectomy for primary liver cancer. World J Gastroenterol, Vol. 9, No. 4, pp. 706-709.

Regimbeau, JM., Farges, O. \& Shen, BY. (1999). Is surgery for large hepatocellular carcinoma justified ? J Hepatol, Vol. 31, pp.1062-1068.

Rui, JA., Zhou, L, Liu, FD., Chu, QF, Wang, SB., Chen, SG., Qu, Q., Wei, X., Han, K., Zhang, N. \& Zhao, HT. (2004). Major hepatectomy without blood transfusion : report of 51 cases.Chinese Medical Journal. Vol.117, No.5, pp.673-676.

Simonnetti, RG., Camma, C., Fiorello, F.et al. (1991). Hepatocellular carcinoma. A worldwide probelem and the major risk factors. Dig Dis Sci. Vol.36, pp.962-972.

Starzl, TE., Bell, RH., \& Beart ,RW .(1975). Hepatic trisegmentectomya and other liver resections. Surg Gynecol Obstet. Vol.141, pp. 429-437.

Sugiura,Y., Nakamura, S. \& Lida S. (1994). Extensive resection of the bile ducts combined with liver resection for cancer of the main hepatic duct junction: a cooperative study of the keio Bile Duct Cancer Study Group . Surgery, Vol.155, pp. 445-451.

Sugita,S., Sasaki, A, Iwaki,K, Uchida, H., Kai, S., Shibata, K. \& Ohtab, S. (2008). Prognosis and postoperative lymphocyte count in patients with hepatocellular carcinoma who received intraoperative allogenic blood transfusion: A retrospective study. EJSO, Vol. 34, pp. 339-345

Thompson, HH., Tompkins, RK. \& Longmire, WP Jr .(1983). Major hepatic resection. A 25year experience. Ann Surg. Vol.197, pp.375-388.

Tjandra, J J., Fan, ST., \& Wong, J. (1991). Peri-operative mortality in hepatic resection. Aust. NZJ , Surg. Vol.61, pp.201-206.

Yamamoto, M., Miura, K. \&Yoshioka, M. (1995). Disease-free survival for 9 years after liver resection for stage IV gallbladder cancer: report of a case. Surg Today, Vol.25, pp.750-753.

Zhou,Li., Rui, JA.\& Wang, SB. (2007). Outcomes and prognostic factors of cirrhotic patients with hepatocellular carcinoma after radical major hepatectomy. World J Surg, Vol. 31, pp. 1782-1787. 
Zacherl, J., Scheuba, C., Imhof, M., et al. (2002). Curret value of intraoperative sonography during surgery for hepatic neoplasms. World J Surg, Vol. 26, No.5, pp. 550-554. 


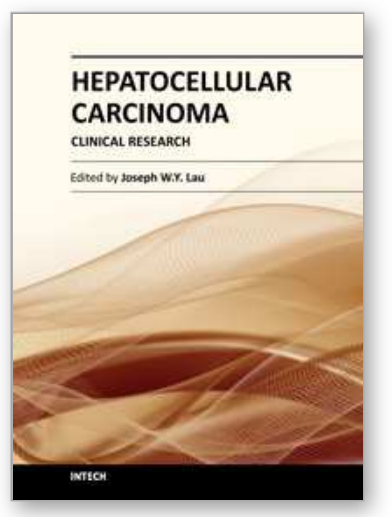

\author{
Hepatocellular Carcinoma - Clinical Research \\ Edited by Dr. Joseph W.Y. Lau
}

ISBN 978-953-51-0112-3

Hard cover, 330 pages

Publisher InTech

Published online 02, March, 2012

Published in print edition March, 2012

This book covers the clinical aspects of hepatocellular carcinoma. This book is a compendium of papers written by experts from different parts of the world to present the most up-to-date knowledge on the clinical aspects of hepatocellular carcinoma. This book is divided into three sections: (I) Diagnosis / Differential Diagnosis; (II) Surgical Treatment; (III) Non-surgical Treatment. There are 19 chapters covering topics from novel diagnostic methods to hepatic lesions mimicking hepatocellular carcinoma, from laparoscopic liver resection to major hepatectomy without allogeneic blood transfusion, from molecular targeted therapy to transarterial radioembolization, and from local ablative therapy to regional therapy. This volume is an important contribution to the clinical management of patients with hepatocellular carcinoma. The intended readers of this book are clinicians who are interested in hepatocellular carcinoma, including hepatologists, liver surgeons, interventional and diagnostic radiologists, pathologists and epidemiologists. General surgeons, general physicians, trainees, hospital administrators, and instruments and drug manufacturers will also find this book useful as a reference.

\title{
How to reference
}

In order to correctly reference this scholarly work, feel free to copy and paste the following:

Jing An Rui (2012). Major Hepatectomy without Allogeneic Blood Transfusion for Hepatocellular Carcinoma, Hepatocellular Carcinoma - Clinical Research, Dr. Joseph W.Y. Lau (Ed.), ISBN: 978-953-51-0112-3, InTech, Available from: http://www.intechopen.com/books/hepatocellular-carcinoma-clinical-research/majorhepatectomy-without-blood-transfusion-for-hepatocellular-carcinoma

\section{INTECH}

open science | open minds

\section{InTech Europe}

University Campus STeP Ri

Slavka Krautzeka 83/A

51000 Rijeka, Croatia

Phone: +385 (51) 770447

Fax: +385 (51) 686166

www.intechopen.com

\section{InTech China}

Unit 405, Office Block, Hotel Equatorial Shanghai

No.65, Yan An Road (West), Shanghai, 200040, China 中国上海市延安西路65号上海国际贵都大饭店办公楼 405 单元

Phone: +86-21-62489820

Fax: $+86-21-62489821$ 
(C) 2012 The Author(s). Licensee IntechOpen. This is an open access article distributed under the terms of the Creative Commons Attribution 3.0 License, which permits unrestricted use, distribution, and reproduction in any medium, provided the original work is properly cited. 